\title{
INCIDENCE OF ARRHYTHMIA AND ASSOCIATED PATIENTS OUTCOME IN HOSPITALIZED ACUTE CORONARY SYNDROME PATIENTS.
}

1. MBBS, Dip Card

PG Student (MD - Cardiology) Isra University Hospital Hyderabad.

2. MBBS, Dip Card, MD (Cardiology) Associate Professor Cardiology National Institute of Cardiovascular Disease

Tando Muhammad Khan.

3. MBBS, MD (Cardiology), FCPS (Cardiology)

Assistant Professor Cardiology Peoples University of Medical \& Health Sciences Nawabshah.

4. FCPS (Medicine), MSc (Gastro) Associate Professor Medicine Peoples University of Medical \& Health Sciences Nawabshah.

Correspondence Address:

Dr. Nandlal Rathi

Department of Cardiology

National Institute of Cardiovascular

Disease

Tando Muhammad Khan.

dr.nand69@gmail.com

Article received on:

28/03/2019

Accepted for publication:

$16 / 12 / 2019$

\section{Bushra Almani ${ }^{1}$, Nandlal Rathi ${ }^{2}$, Jagdesh Kumar ${ }^{3}$, Abdul Aziz Sahito ${ }^{4}$}

ABSTRACT... Objectives: The aim behind this study was to scientifically determine the incidence of arrhythmias and associated patient's outcome in hospitalized acute coronary syndrome patients. Study Design: Observational Hospital Based study. Setting: Department of Cardiology, Isra University Hospital Hyderabad. Period: One year from 26 $6^{\text {th }}$ March 2018 to $25^{\text {th }}$ March 2019. Material \& Methods: A total of 177 patients were included having age 20 to 70 years both male and female. Data were entered and analyzed by using Statistical Package for the Social Sciences version 20.0. Results: The mean age of patients was $48.23 \pm 12.9$ years with predominantly males $(58.19 \%)$. The most commonly observed risk factor in our study was cigarette smoking ( $\mathrm{N}=96,54.23 \%)$ The overall incidence of arrhythmias irrespective of their origin within acute phase was observed $12.99 \%(N=23)$ out of total 151 admitted patients. Among these 23 cases, the ventricular arrhythmias were more common than atrial arrhythmias, $(\mathrm{N}=17,73.91 \%)$ and $(\mathrm{N}=06,26.08 \%)$, respectively. Only $2(8.69 \%)$ cases experienced complications related to arrhythmias. Conclusion: Ventricular origin arrhythmias are more commonly observed in our study and were also associated with fatal complications as compared to atrial arrhythmias.

Key words: $\quad$ Arrhythmias, Acute Coronary Patients, In-Hospital Outcome.

Article Citation: Almani B, Rathi N, Kumar J, Sahto AA. Incidence of arrhythmia and associated patients outcome in hospitalized acute coronary syndrome patients. Professional Med J 2020; 27(9):1790-1794.

DOI: 10.29309/TPMJ/2020.27.09.3459

\section{INTRODUCTION}

The term acute coronary syndrome (ACS) refers to any group of clinical symptoms compatible with acute myocardial ischemia and includes unstable angina (UA), Non - ST-segment elevation myocardial infarction (NSTEMI), and STsegment elevation myocardial infarction (STEMI). 02Knowledge of the occurrence of arrhythmias associated with acute coronary syndrome (ACS) is limited in contemporary clinical practice. Recent research on arrhythmias has been in the context of genetics and interventions, rather than centered on clinical conditions such as ACS. ${ }^{1,2}$

There is already well established pathophysiology in relation with the development of arrhythmias and electrolytes imbalance like increase or decrease in serum potassium and magnesium levels are associated with increased number of ventricular arrhythmias which can be silent at times and can be fatal. Duration of acute myocardial infarction has a direct relation with the incidence of atrial or ventricular arrhythmias. These patients are should be monitored continuously during acute course of hospitalization. ${ }^{3}$

Most common deaths are due to ventricular origin arrhythmias as compared to a trial. Atrial fibrillation is the most common atrial arrhythmias but they are rarely fatal but may cause stroke if left untreated. Treatment of such patients depends upon hemodynamic stability and instability, if the patient is hemodynamically unstable then direct current cardioversion is the recommended therapy. ${ }^{4-6}$

Great diversity has been observed while looking at the international data regarding bradyarrhythmias in patients with ACS which is ranging from $0.3 \%$ to $18 \%$ and some studies shows complete heart 
block ranging from $10 \%$ to $15 \%$. Fatal arrhythmias wither atrial or ventricular origin occurs in approximately $50 \%$ of the patients and considered to be the first sign of acute coronary syndrome. Data from Europe has shown mortality rate in acute coronary syndrome patients is $65 \%$ to $80 \%$ due to ventricular arrhythmias and $5 \%$ to $20 \%$ in bradyarrhythmias ${ }^{7}$, while there is no scientific study has been present from our side which shows the actual burden of these arrhythmias in patient admitted with ACS that is why this study has been conducted to provide the scientific data and improve survival rate.

\section{MATERIAL \& METHODS}

A prospective observational study has been conducted in the department of Cardiology which is a part of a tertiary care Hospital, Isra University Hospital Hyderabad and included all the patients with ACS and age $\geq 20$ years and $\leq 70$ years of both males and females after taking written and informed consent were included in our study.

Patients after admission were kept under observation and monitorization for at least 24 hours in which they were assessed for the possible conversion from ACS into myocardial infarction. Serial ECGs were performed for any change in ECG from baseline and suggesting underlying rhythm abnormality. Detection of arrhythmia were done based on the attached monitor and confirmed after performing immediate long lead through cardiac defibrillator.

Patients were labeled as acute coronary syndrome if they admitted with typical reterosternal chest pain along with ST-Segment deviation on ECG, or positive cardiac biomarkers or meeting all of them. The findings, age, sex, social class, education status, risk factors and outcome were entered in a predesigned questionnaire for data collection and Statistical Package for Social Sciences (SPSS) Version 21 was used for data entry and analysis.

\section{RESULTS}

A total of 177 patients were selected for this study. The study subjects consisted of 103 males (58.19\%) and 74 (41.80\%) females. The mean age of patients was $48.23 \pm 12.9$ years.

Figure-1 shows percentage of risk factors in our study subjects. The most commonly observed risk factor in our study was cigarette smoking ( $\mathrm{N}$ $=96,54.23 \%$ ), followed by Hypertension ( $\mathrm{N}=$ $79,44.63 \%)$, Diabetes Mellitus ( $\mathrm{N}=45,25.42 \%)$, Dyslipidemia ( $\mathrm{N}=42,23.72 \%$ ), and History of Ischemic Heart Disease ( $N=23,12.99 \%)$.

The overall incidence of arrhythmias irrespective of their origin within acute phase was observed $12.99 \%(\mathrm{~N}=23)$ out of total 177 admitted patients. Among these 23 cases, the ventricular arrhythmias were more common than atrial arrhythmias, $(\mathrm{N}=17,73.91 \%)$ and $(\mathrm{N}=06$, $26.08 \%$ ), respectively. The most common ventricular arrhythmia was premature ventricular contractions ( $\mathrm{N}=5,39.13 \%)$ and only a single case of Torsa De Pointes (4.34\%) were observed while the most common atrial origin arrhythmia was atrial fibrillation ( $\mathrm{N}=3,47.82 \%)$ while only one patient $(4.34 \%)$ had experienced atrial flutter presented via Table-l.

The overall outcome of patients with arrhythmias was presented via Figure-2. Only 2 (8.69\%) cases experienced complications related to arrhythmias amongst all $(\mathrm{N}=23), 1$ case developed stroke and 1 (4.34\%) case died due to fatal ventricular arrhythmia (4.34\%), rest of the 21 cases (91.3\%) who experienced arrhythmias were treated and discharged to home.

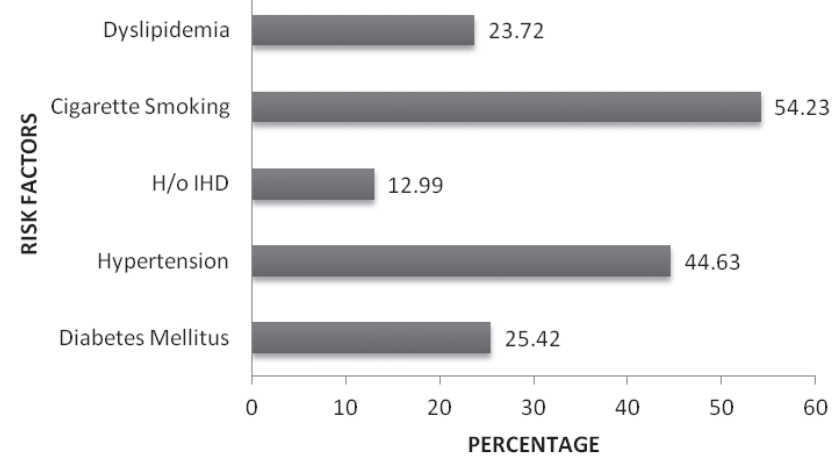

Figure-1. Risk factors observed in patients with ACS associated arrhythmias. $(\mathrm{N}=177)$ 


\begin{tabular}{|l|c|c|}
\hline \multicolumn{1}{|c|}{ Type of Arrhythmias } & $\mathbf{n}$ & $\%$ \\
\hline Non-Malignant & 21 & 91.3 \\
\hline Malignant & 2 & 8.69 \\
\hline Ventricular & $\mathbf{( n = 1 7 )}$ & \\
\hline PVCs & 6 & 39.13 \\
\hline Ventricular Tachycardia & 5 & 30.43 \\
\hline Ventricular Fibrillation & 3 & 13.04 \\
\hline Torade de ponites & 1 & 4.34 \\
\hline VT plus VF & 2 & 8.69 \\
\hline Atrial & $\mathbf{( n = 0 6}$ & \\
\hline SVT & 2 & 8.69 \\
\hline Atrial Fibrillation & 3 & 47.82 \\
\hline Atrial Flutter & 1 & 4.34 \\
\hline
\end{tabular}

Table-I. Type of arrhythmias. $(n=23)$

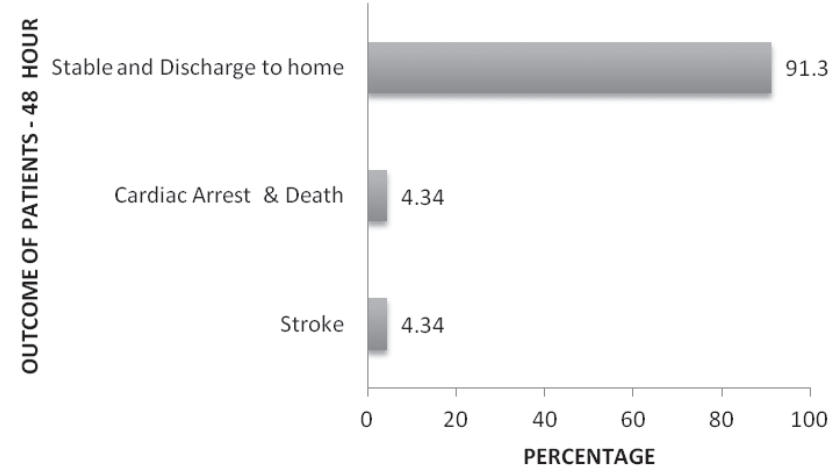

Figure-2. Outcome of patients with arrhythmias. $(\mathrm{N}=23)$.

\section{DISCUSSION}

The occurrence of atrial but particularly ventricular arrhythmias in patients with ACS is of substantial importance in the clinical decisionmaking process. Large multinational studies have been conducted in recent years to determine the magnitude and prognosis associated with arrhythmias in patients hospitalized with ACS. Our single centered data expand this knowledge by including the incidence, associated factors, and outcomes of patients with ACS complicated by the development of arrhythmias. ${ }^{8,9}$

Time is crucial in managing patients with acute coronary syndrome because more than $90 \%$ of patients with acute myocardial infarction experience some sort of arrhythmias from to onset of chest pain up to 48 hours(9). In this study, the overall incidence of arrhythmias irrespective of their origin within acute phase ( $<48$ hours) was observed $12.99 \%(\mathrm{~N}=23)$ out of total 177 admitted patients. Among these 23 cases, the ventricular arrhythmias were more common than atrial arrhythmias, $(\mathrm{N}=17,73.91 \%)$ and $(\mathrm{N}=06$, $26.08 \%$ ), respectively. On the other hand, a study conducted by Ahmad S. Hersi and colleagues in a multicentre Saudi hospitals have shown the incidence of ventricular arrhythmias were occurred in $3.3 \%(N=168)$ of patients with ACS. ${ }^{10}$

In our study, the mean age of patients admitted with ACS was $48.23 \pm 12.9$ years which is quite different from the study conducted previously in which their mean age of patients was more declined towards elder groups of people. ${ }^{11}$

Atrial fibrillation is common among patients with cardiovascular disease and is a frequent complication of the acute coronary syndrome. Atrial fibrillation is one of the most important atrial arrhythmias among patients suffering from acute myocardial infarction and its incidence vary greatly from $5 \%$ to $23 \%$ and In the present investigation, 3 patients (47.82\%) has experienced atrial fibrillation while they were admitted in hospital. When comparing the data from international studies (7.5\%), higher rates are observed in our study this could be due to number of cases in our study are less and the percentage has not the actual real picture which could be observed when number of cases become more. ${ }^{12-14}$

Complications are commonly seen in all forms of acute coronary syndrome, although the frequency and extent vary with the severity of ischemia and infarction. Major mechanical, structural and electrical complications are seen with transmural infarction. Perron $A D$ et al found that arrhythmia complicating ACS was higher than other type of complications. ${ }^{15}$

In our study the malignant arrhythmias were of ventricular origin among them a combination of sustained VT along with VF were associated with poor outcome such as death and cerebrovascular accident in acute hospitalized ACS patients. A previously conducted study by Ferguson, J.D et al. has shown that VF was the most lethal 
arrhythmia (16\% of all cases with prolonged dispersion), followed by VT, observed in $5 \%$ of the sample. ${ }^{16}$

One of the major complications of arrhythmias is the development of stroke, in a previously conducted study, the total number of stroke cases in more than 35,000 admitted patients was less than $1 \%$ ( $\mathrm{N}=310$ cases) and among them 100 cases $(32.6 \%)$ were fatal and these numbers are higher in patients with STEMI as compared with Non-STEMI. In contrast, the incidence of stroke among complicated ACS patients due to arrhythmias was $4.34 \% .{ }^{17}$

This research only recognized the existing association between the development of complications and adverse events, but did not assess variables that might predict whether these associations were in relation to the degree of reperfusion or patency achieved by the affected coronary vasculature and responsible for the ACS. Therefore, this must be the starting point for future research.

\section{CONCLUSION}

Great proportion of patients with ACS developed arrhythmias in 1st 48 hours of onset of symptoms. Smoking, hypertension, and diabetes mellitus were identified as major risk factors. The overall incidence of arrhythmias irrespective of their origin within acute phase was observed $12.99 \%$ ( $\mathrm{N}=$ 23) out of total 177 admitted patients. Among this majority were ventricular originated arrhythmias than atrial arrhythmias. Amongst all, patients with documented episode of arrhythmias, most of the patients experienced non-malignant arrhythmias and only 2 patients experienced malignant arrhythmias.

Copyright@ 16 Dec, 2019.

\section{REFERENCES}

1. Wallentin L, Lindhagen L, Arnstrom E, Husted S, Janzon $M$, Johnsen SP, et al. Early invasive versus noninvasive treatment in patients with non-ST-elevation acute coronary syndrome (FRISC-II): 15 year followup of a prospective, randomised, multicentre study. Lancet 2016 Oct 15; 388(10054):1903-11.
2. Freisinger E, Sehner S, Malyar NM, Suling A, Reinecke $H$, Wegscheider K. Nationwide routine-data analysis of sex differences in outcome of acute myocardial infarction. Clinical cardiology. 2018 Aug;41(8):1013-21.

3. Auffret V, Leurent G, Gilard M, Hacot JP, Filippi E, Delaunay $R$, et al. Incidence, timing, predictors and impact of acute heart failure complicating ST-segment elevation myocardial infarction in patients treated by primary percutaneous coronary intervention. Int $\mathrm{J}$ Cardiol 2016 Oct 15; 221:433-42.

4. Franck C, Filion KB, Eisenberg MJ. Smoking cessation in patients with acute coronary syndrome. The American journal of cardiology. 2018 May 1;121(9):110511.

5. Berwanger O, Santucci EV, de Barros E Silva PGM, Jesuino IA, Damiani LP, Barbosa LM, et al. Effect of loading dose of atorvastatin prior to planned percutaneous coronary intervention on major adverse cardiovascular events in acute coronary syndrome: The SECURE-PCI Randomized Clinical Trial. JAMA 2018 Apr 3; 319(13):1331-40.

6. Udell JA, Fonarow GC, Maddox TM, Cannon CP, Frank Peacock W, Laskey WK, Grau-Sepulveda MV, Smith EE, Hernandez AF, Peterson ED, Bhatt DL. Sustained sex-based treatment differences in acute coronary syndrome care: insights from the American Heart Association Get With the Guidelines Coronary Artery Disease Registry. Clinical cardiology. 2018 Jun;41(6):758-68.

7. Trappe HJ. Tachyarrhythmias, bradyarrhythmias and acute coronary syndromes. J Emerg Trauma Shock 2010 Apr; 3(2):137-42.

8. Biasco L, Radovanovic D, Moccetti M, Rickli H, Roffi M, Eberli F, Jeger R, Moccetti T, Erne P, Pedrazzini G. New-onset or pre-existing atrial fibrillation in acute coronary syndromes: two distinct phenomena with a similar prognosis. Revista Española De Cardiología (English Edition). 2019 May 1;72(5):383-91.

9. Norsa'adah B, Che-Muzaini CM. Association of comorbidity and treatment with the complications of acute coronary syndrome in young patients less than 45 years. Malays J Med Sci 2018 Feb; 25(1):4252.

10. Hersi AS, AlHabib KF, Alfaleh HF, AINemer K, AISaif S, Taraben $A$, et al. Incidence of ventricular arrhythmia and associated patient outcomes in hospitalized acute coronary syndrome patients in Saudi Arabia: findings from the registry of the Saudi Project for Assessment of Acute Coronary Syndrome (SPACE). Ann Saudi Med 2012 Jul; 32(4):372-7. 
11. Panduranga $P$, Sulaiman KJ, Al-Zakwani I, AlHabib KF, Hersi A, Suwaidi JA, et al. Acute coronary syndrome in indian subcontinent patients residing in the middle east: Results from gulf registry of acute coronary events II. Angiology 2015 Oct; 66(9):818-25.

12. Komiyama K, Nakamura $M$, Tanabe $K$, Niikura $H$, Fujimoto $H$, Oikawa $K$, et al. In-hospital mortality analysis of Japanese patients with acute coronary syndrome using the Tokyo CCU Network database: Applicability of the GRACE risk score. J Cardiol 2018 Mar; 71(3):251-8.

13. Huffman JC, Beale EE, Beach SR, Celano CM, Belcher AM, Moore SV, et al. Design and baseline data from the gratitude research in acute coronary events (GRACE) study. Contemp Clin Trials 2015 Sep; 44:119.
14. Squires K, Feinberg J, Bridge DA, Currier J, Ryan R, Seyedkazemi S, et al. Insights on GRACE (Gender, Race, And Clinical Experience) from the patient's perspective: GRACE participant survey. AIDS Patient Care STDS 2013 Jun; 27(6):352-62.

15. Perron AD, Sweeney T. Arrhythmic complications of acute coronary syndromes. Emerg Med Clin North Am 2005 Nov; 23(4):1065-82.

16. Ferguson JD, Brady WJ, Perron AD, Kielar ND, Benner JP, Currance SB, et al. The prehospital 12-lead electrocardiogram: impact on management of the out-of-hospital acute coronary syndrome patient. Am J Emerg Med 2003 Mar; 21(2):136-42.

17. Budaj A, Eikelboom JW, Mehta SR, Afzal R, Chrolavicius S, Bassand JP, et al. Improving clinical outcomes by reducing bleeding in patients with non-ST-elevation acute coronary syndromes. Eur Heart J 2009 Mar; 30(6):655-61.

\begin{tabular}{|c|c|c|c|}
\hline \multicolumn{4}{|c|}{ AUTHORSHIP AND CONTRIBUTION DECLARATION } \\
\hline Sr. \# & Author(s) Full Name & Contribution to the paper & Author(s) Signature \\
\hline 1 & Bushra Almani & & \\
\hline 2 & Nandlal Rathi & All authors have contributed & \\
\hline 3 & Jagdesh Kumar & equally. & \\
\hline 4 & Abdul Aziz Sahito & & \\
\hline
\end{tabular}

